\title{
Temporal Accommodation in Government-public Interactions on Chinese Government Weibo in Emergency Context
}

\author{
Wei Liu ${ }^{1}$, Wen-yu Liu ${ }^{2}$ \\ ${ }^{1}$ School of Foreign Languages Dalian University of Technology, Liaoning Province, China \\ ${ }^{2}$ School of Foreign Languages Dalian University of Technology, Liaoning Province, China \\ karen_lw@163.com, liuwy@dlut.edu.cn
}

\begin{abstract}
Chinese Government Weibo enables civic engagement and political participation, and arouses unprecedented communication conflict between government and public. This study intends to investigate communication strategies employed in emergency management on government Weibo under the guidance of Communication Accommodation Theory, according to which interactants employ convergence, divergence or maintenance strategy to negotiate social distance through modifying the communication moves. This research presents and analyzes a case of Shanghai government Weibo account@ @hanghaiditieshmetro on examining communication processes empirically in terms of temporal cues. The findings imply that the government shall adapt itself to the egovernment era and give continual attention to the online public voices, according to which tune its behaviors to get a win-win result.

Index Terms - Computer-mediated Communication, Communication Strategy, Chinese Government Weibo, Communication Accommodation Theory, Emergency.
\end{abstract}

\section{Introduction}

Government Weibo provides a Web2.0 channel for mutual interaction between government and public. Government utilizes Weibo as pipeline of information sharing [1] and public communication [2][3]. As a tool for government to catch public voice, Weibo facilitates the interactions between government and public by authorizing the government to deliver the news and guiding the orientation in public opinion effectively. At the same time, to meet the demand for immediate response, emergency management requires effective and rapid information exchange between government and public. In the wake of emergency, Government Weibo is expected to fulfill its reporting function to satisfy public's needs for the truth.

Government Weibo also brings unprecedented challenges to the responding mechanism of e-government, as it requires the government account of a faster pace on information release and a more accurate language in terms of the content. Besides, government and public may also frequently encounter communication problems caused by hierarchies of power that interweave offline and online contexts [4], they are inevitably invoke communication strategies to address those problems through adjusting their languages. Therefore, to look into the communication strategy, identity, context and language are three inseparable elements when it comes to the communication between government and public. In this study, Government Weibo provides online discourse for analysis as one kind of Computer Mediated Communication.
Communication Accommodation Theory (CAT), as one of the most preeminent frameworks in the social psychology of language, suggests that communicators use strategic behaviour, mainly based on language, to gain approval or to show distinctiveness during interactions, in which process communicators accommodate their communication styles to be similar to or different from their partners in order to achieve various relational goals such as group identification or interpersonal solidarity [5]. CAT serves this study a tool to elucidate the behaviour shift mainly informed by temporal cues, thus interpreting and concluding the strategies that government and public used in the communication.

\section{Literature Review}

A. Study on Chinese Government Weibo

Reference [6] approached government Weibo in terms of definition, content design, characteristics, operation system and challenges. Since microblogging can facilitate civic engagement and political participation [7], reference [8] found that Chinese local government microblogs function largely as 'beta-institutions' experimenting with ways to interact and negotiate with their microblog publics and microblog service providers and aim to improve social management and political legitimacy. Reflecting on microblogging in the context of the Chinese Internet, reference [9] argued that its successes in breaking scandals and mobilizing opinion against recalcitrant officials should not mask the reality that the government is utilizing the microblogosphere to its own advantage. Building on the fact that more research links the informational uses of the mobile phone as an entry to increase involvement in civic and political life, reference [10] explored the role of smart phone on civil discourse engagement.

Although the role of Weibo in the government management has received a great deal of attention, research has been limited to how it is run effectively as an emerging media. The interactivity between the government and public through microblogging has been rarely addressed, especially from a sociolinguistic perspective.

\section{B. CAT: Analysis Tool for Computer Mediated Communication}

According to CAT, there are mainly three communication patterns, namely convergence, divergence and maintenance. Convergence means that the communicators 
may convert to their counterpart's language use by using the same language structure, accent, dialect, speech rate, and lexical diversity in order to gain acceptance or approval [11]. Conversely, as communicators adopt divergent behaviour, "speakers dissociate with or show disapproval of others by making their speech diverge from that of the other" [12]. Maintenance is a strategy by which the communicators preserve one's linguistic style without accommodative adjustments, even to the point of ignoring the accommodative attempts made by the communicator [13]. Thus, maintenance is also viewed as a kind of divergence strategies to a certain extent.

CAT makes dynamic analysis possible in a variety of contexts of how communicators continuously accommodate to the perceived language characteristics of their counterparts, linking language, context and identity together and considering these three elements inseparable in the utilization of CAT. It mainly draws upon Social Identity Theory [14] to suggest motivations for accommodation, especially when the intergroup interactions are considered. In reference [15]'s definition, social identity is "the individual's knowledge that he belongs to certain social groups, together with some emotional and value significance to him of the group membership". Specifically, in order to signal that the communicators belong to a similar social group, they may accommodate to each other for seeking acceptance and identification. In contrary, the individuals of different groups can employ processes of distinctiveness [16] to try to make themselves positively distinct from the out-group in order to enhance their social identity [15].

Some researchers have tried employing CAT to study the computer-mediated communication (CMC), and reference [17] discussed the lexical convergence in E-mail by investigating the use of politeness terms and concluded that interlocutors converge structurally as well as lexically. Lexical convergence influences perceptions of rapport [18] and varies by level of trust [19] [20]. Compared with Face to Face communication, the exploration of CMC under CAT framework focuses more on the message length and duration (shorter or longer response times) concerning the structural variables because of the lack of nonverbal cues [21]. In email, individuals tend to have very consistent response latencies [22], in which the faster response latencies lead to more positive interpersonal perceptions in supportive emails [23], in task emails [21] and in job-seeking emails [24]. Similarly, longer messages on an email discussion list resulted in more positive interpersonal perceptions [6].

\section{Theoretical Framework}

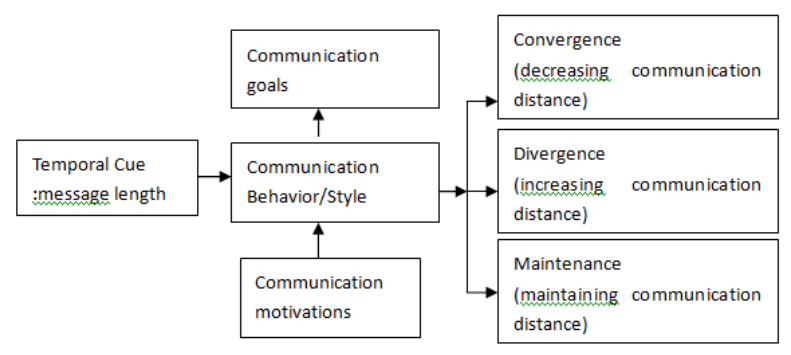

Fig.1 Communication Accommodation Theory (CAT), based on [25] [26].

From a CAT perspective, it is important to investigate the effects of different temporal cues and the extent to which interactants adapt to each other's use of these cues [27]. Reference [28] identified pace as an important temporal structure in CMC, which is influenced by the structural variables such as the message length (shorter or longer messages) and duration (shorter or longer response times). Temporal convergence has been documented in synchronous online chats [7] and longer messages on an email discussion list resulted in more positive interpersonal perceptions [6].

\section{Research Procedure}

This study adopts case study to offer researchers the opportunity to examine phenomena in depth by focusing on one setting [29] [30]. In this study, Sina Weibo, set up in 2009, the biggest Chinese microblogging platform, is taken as the study subject as it is often the first place for news to break and hosts discussions about breaking news [31](Yong, 2012). The posts and comments of @Shanghaiditieshmetro during an emergency in which rear-end collision occurred to two metros of Shanghai Metro Line 10 on 27 September, 2011 are collected as data.

\section{A. Incident Identification}

The reason of choosing such an incident lies in its prototypicality and high interactivity of communication between government and public, as the accident involves public transportation safety which can directly exert influence on the interest even life security of public. Therefore, such an event will draw considerable attention from public and the posts from government and comments from public in this process are inherently goal-oriented and highly strategic. The data is composed of two parts, one is posts of @ Shanghaiditie -shmetro and the other is the comments from public.

\section{B. Data Collection, Reduction and Sorting}

Although the accident happened on 27 September 2011, the duration of its aftermath has reached to the next day. Therefore, the data of two days were collected for analysis in this study. In these two days, the user @ Shanghaiditieshmetro posted 47 pieces of messages and reposted 4 pieces of messages without comments and 10 with comments. All the messages are reposted and commented by public although the total number of repost and comments vary over time. As several posts were commented more than thousand times, the data is collected according to the chronological order, namely, 
only the earliest 150 pieces of comments are collected for this research. At the same time, the posts which were commented lower than 50 times are not included in the data as well as their comments. After data reduction, there are totally 45 pieces of posts from @ Shanghaiditieshmetro and 1,822 pieces of comments from public.

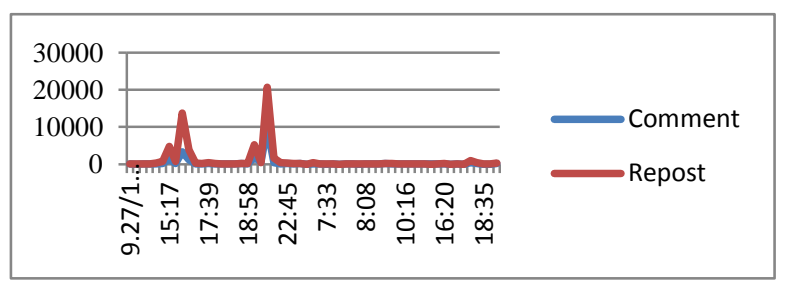

Fig. 2 Change Curve of Practices of Repost and Comments over Time

This study concentrates on two particular behaviours of public throughout: posting and commenting, thus the frequency of repost and number of comments of the posts are calculated for better interpretation of dynamic change of these two practices with the time of posts being considered as the variable. Five value peaks are presented in both the comment curve and the repost curve while the overall frequency of repost is higher than the total number of the comments, among which the second and the fourth one are particularly salient. In this sense, public tends to repost the declarative information to their followers functioning as dissemination tool. The behavioural variation may determine the point at which that public engagement level is changed as the baseline of event phases, as the shifts in information production and attention reveal a tendency for users engaging with media events (Yu$\mathrm{Ru}$ Lin et al. 2014). Therefore, the period from 14:14 p.m. to $15: 17$ p.m. is the pre-event phase, from 15:17 p.m. to $18: 58$ p.m. is the outbreak phase, and from $18: 58$ p.m. to the end of the day is the aggravation phase, the next day is the fall phase.

\section{Data Analysis}

As the non-verbal behaviours (e.g., gesture and posture), features of vocalization (e.g., accent and speech rate) are often unavailable as tools for accommodation in CMC, this research mainly examines the data respectively, in terms of the temporal cues (longer or shorter message).

\section{Results and Discussion}

The sample collected from the pre-event phase includes 7 posts from the government and 298 pieces of comments from public. To examine the temporal convergence in message length, each post and its comments are considered as one adjacent sequence. As it is one to many communication model, the average words of public is calculated for analysis.

Tab. 1. Mean and Standard Deviation of Characters per Phase

\begin{tabular}{|l|l|l|l|l|}
\hline Mean \& SD (Chinese Character) & Pre-event & Outbreak & Aggravation & Fallout \\
\hline Government & $\mathrm{M}=82.86 \mathrm{SD}=34.55$ & $\mathrm{M}=66.62 \mathrm{SD}=38.48$ & $\mathrm{M}=82.86 \mathrm{SD}=34.55$ & $\mathrm{M}=88.00 \mathrm{SD}=48.16$ \\
\hline Public & $\mathrm{M}=21.219 .74<\mathrm{SD}<18.97$ & $\mathrm{M}=24.9114 .34<\mathrm{SD}<27.73$ & $\mathrm{M}=21.43 \quad 16.70<\mathrm{SD}<27.15$ & $\mathrm{M}=28.0618 .26<\mathrm{SD}<35.99$ \\
\hline
\end{tabular}

The mean and standard deviation scores of characters for the entire incident are presented in Tab. 1. The mean value of characters of messages of these two groups shows that the government used much longer message than public did in that the government is responsible for releasing information as effectively as possible within 140 characters. While the number of characters sent by public is relatively less than that of government, it varies to a less extent than that of government does. All in all, the government posted longer messages and they displayed greater variation in terms of length.

Tab. 2. Correlations between Message Length of Government and Public

\begin{tabular}{|l|l|l|}
\hline & $\mathrm{G}$ & $\mathrm{p}$ \\
\hline g Pearson Correlation & 1 & .226 \\
Sig. (2-tailed) & & .626 \\
Sum of Squares and & 7162.857 & 114.429 \\
Cross-products & 1193.810 & 19.071 \\
Covariance & & \\
$\mathrm{N}$ & 7 & 7 \\
\hline $\mathrm{p}$ Pearson Correlation & .226 & 1 \\
Sig. (2-tailed) & .626 & \\
Sum of Squares and & 114.429 & 35.714 \\
Cross-products & 19.071 & 5.952 \\
Covariance & & \\
$\mathrm{N}$ & 7 & 7 \\
\hline
\end{tabular}

After probing into the mean and standard deviation of words, Pearson correlations are run to investigate the interactive influence exerted by each other in terms of message length. Tab. 2 shows that in the pre-event phase the government's $(\mathrm{M}=82.86$ words, $\mathrm{SD}=34.55)$ and public's $(\mathrm{M}=21.21$ words, $\mathrm{SD}=2.41)$ message lengths are weakly correlated, and the significance level shows that this sample hardly attribute to the statistical analysis. Thus in the pre-event phase, maintenance exists in message length of the government and public. In a sense, both the government and public hardly attend to and adapt to each other in terms of message length in such phase. The Pearson's test have been run in the rest three phases, the similar conclusion can be drawn.

The results demonstrate that the government and public adopted maintenance strategy in terms of message length, meaning that they hardly adjust the length of their discourse towards that of the counterpart's. This phenomenon is partially related to the fact that Weibo is a platform for free chat by which the length does not have to be adjusted for accommodation. The response time is an unavailable tool due to the asynchronous feature of Weibo online interactions, by which the participants can send messages and construct interaction at any time. 


\section{Conclusion}

This study provides evidence for the occurrence of communication strategies on government Weibo in emergency context employed by government and public. It indicates that government and public to certain extent tune their communication behaviours in form of convergence, divergence or maintenance to negotiate intergroup distance. In terms of message length, it appears that government and public employ maintenance strategy with no evidence of adjusting it.

The study may shed light on how emergency responders, namely, the operators of government accounts or the responsible party better cope with the emergent incident through effective communication with public in the aftermath. In such a virtual public sphere, government and public share a relatively equal communication platform, facilitating successful communications in the wake of emergency fulfilled on the basis of efficient behavioural shifts driven by the influence exerted by each other at the language level. Further, to reinforce the sound relationship between government and public with employment of Weibo and to make full use of such communication tool efficiently to guide public opinions has become the most urgent requirement for Chinese government. The findings imply that the government shall adapt itself to the e-government era and give continual attention to the online public voices, according to which tune its behaviours to get a win-win result.

\section{References}

[1] D. Jr. Landsbergen, and G. Jr. Wolken, "Realizing the Promise: Government Information Systems and the Fourth Generation of Information Technology," Public Administration Review, vol. 61, no. 2, pp. 206-220, 2001.

[2] B. Bimber, "The internet and citizen communication with government: Does the medium matter?" Political Communication, vol. 16, pp. 409428, 1999.

[3] C. Maciel, L. Roque and A. C. Bicharra, "Interaction and communication resources in collaborative e-democratic environments: The democratic citizenship community," Information Polity, vol. 15, no. 1/2, pp 73-88, 2010.

[4] P. Ruth, "The linguistics of self-branding and micro-celebrity in Twitter: The role of hashtags," Discourse \& Communication, vol. 6, no. 2, pp 181-201, 2012.

[5] H. Giles, N. Coupland and J. Coupland, Contexts of accommodation: Developments in applied sociolinguistics, Cambridge: Cambridge University Press, 1991.

[6] Y. Liu, D. Ginther, and P. Zelhart, "How do frequency and duration of messaging affect impression development in computer-mediated communication?" Journal of Universal Computer Science, vol. 7, pp. 893-913, 2001.

[7] A. de Siqueira and S. C. Herring, "Temporal patterns in student-advisor instant messaging exchanges: Individual variation and accommodation," 2009. Available at: http://ieeexplore.ieee.org/stamp/stamp.jsp?arnumber=4755333

[8] S. Jesper, "Official microblogging and social management by local governments in China," China Information, vol. 28, no. 2, pp. 189-213, 2014.

[9] S. Jonathan, "China's Weibo: Is faster different?" New Media \& Society, vol. 16, no. 1, pp. 24-37, 2014.

[10] W. Ran, "Texting, tweeting, and talking: Effects of smart phone use on engagement in civic discourse in China," Mobile Media \& Communication, vol. 2, no. 1, pp. 3-19, 2014.
[11] H. Giles and N. Coupland, "Accommodating Language," in Giles H, Coupland N (eds) Language: Contexts and Consequences, Great Britain: Open University Press, 1991.

[12] R. L. Street and R. Hopper, "A model of speech style evaluation," in Ryan EB, Giles H. (eds) Attitudes toward language variation: Social and applied contexts, London: Edward Arnold, pp. 175-188, 1982.

[13] A. Ginisci, "Sequential Strategies of accommodation: A new method in courtroom," British Journal of Social Psychology, vol. 44, no.4, pp. 612$643,2005$.

[14] M. A. Hogg, and D. Abrams, Social Identifications: A Social Psychology of Intergroup Relations and Group Processes, London: Routledge, 1988.

[15] H. Tajfel, and M. Billig, "Familiarity and categorization in intergroup behaviour," Journal of Experimental Social Psychology, vol. 10, pp 159-170, 1974.

[16] H. Giles, and P. Smith, "Accommodation Theory: Optimal Levels of Convergence," in Giles H, St. Clair, Robert N (eds) Language and Social Psychology, Baltimore: Basil Blackwell, 1979.

[17] U. Bunz, and SW. Campbell, "Politeness accommodation in electronic mail," Communication Research Reports, vol. 21, no. 3, pp. 11-25, 2004.

[18] C. W. Crook, and R. Booth, "Building rapport in electronic mail using accommodation theory," SAM Advanced Management Journal, vol. 62, pp. 4-13, 1997.

[19] L. E. Scissors, A. G. Gill and D. Gergle, (2008) Linguistic mimicry and trust in text - based CMC. Available at: http://collablab.northwestern.edu/pubs/CSCW2008-ScissorsEtAlLinguisticMimicry.pdf

[20] LE. Scissors, AG. Gill and D. Gergle, "'You Can Trust Me,' 'I Can Trust You': Linguistic Accommodation and Trust in Text - based CMC," 2009.Available at: http://citation.allacademic.com/meta/p_mla_apa_research_citation/3/0/1/ 0/4/pages301043/p301043-1.php

[21] J. B. Walther, and L. C. Tidwell, "Nonverbal cues in computer-mediated communication, and the effect of chronemics on relational communication," Journal of Organizational Computing, vol. 5, pp. 355378, 1995.

[22] Y. M. Kalman, G. Ravid, D. R. Raban, et al, "Pauses and response latencies: A chronemic analysis of asynchronous CMC," Journal of Computer Mediated Communication, vol. 12, no. 1, pp. 1-23, 2006.

[23] A. M. Ledbetter, "Media use and relational closeness in long-term friendships: Interpreting patterns of multimodality," New Media \& Society, vol. 10, no.4, pp. 547-564, 2008.

[24] Y. M.. Kalman, and S. Rafaeli, "Online pauses and silence: Chronemic expectancy violations in written computer-mediated communication," Communication Research, vol. 38, pp. 54-69, 2011.

[25] C. Gallois, A. Franklyn-Stokes, H. Giles, and N. Coupland, "Communication accommodation in intercultural encounters," in Y. Y. Kim \& W. B. Gudykunst (Eds.), Theories in intercultural communication, Newbury Park, CA: Sage, 1988.

[26] M. Guirdham, Communication across cultures. Hundmills, Basingstoke, Hampshire: Mac-Millian Press, 1999.

[27] A. R. Monica, M. M. Kris, and O. S. Craige, "Communication Accommodation in instant messaging: An examination of temporal convergence," Journal of Language and Social Psychology, vol. 32, p. 84, 2013.

[28] B. W. Hesse, C. M. Werner, and I. Altman, "Temporal aspects of computer-mediated communication," Computers in Human Behavior vol. 4, pp. 147-165, 1988.

[29] A. Bryman, Social Research Methods. New York: Oxford University Press, 2001.

[30] J. Creswell, Research Design: Qualitative \& Quantitative Approaches. Thousand Oaks CA: Sage Publications, 1994.

[31] H. Yong. (2012) Spreading the news. Arts and Humanities Citation Index. 